\title{
COLONIAL TERRITORIES
}

T HE report on the Colonial Territories for $1957-$ $58^{*}$ provides the usual conspectus of political, economic, financial and social developments in these territories against which the achievements to be recorded in greater detail in "Colonial Research, 1957-58" are to be considered. Some of this material, outlined in the 22-page chapter entitled "Research and Surveys", has also appeared in reports from various Colonial research organizations already noted in Nature, and for this reason, while this chapter in the present report is the one of most direct interest to the scientist, consideration of research in the Colonial territories is deferred until the fuller report, "Colonial Research, 1957-58", is published in due course.

Recruitment through the Colonial Office continued at the same general level as last year, but recruitment for the Federation of Malaya was gradually transferred to the High Commissioner for that territory. About the same number of administrative and medical officers were appointed as in 1956, but the number of educational appointments increased and the number of civil, mechanical and electrical engineers and agricultural officers recruited decreased. The total overseas appointments through the Colonial Office was 1,296 as compared with 1,286 in 1956 , leaving 1,385 unfilled vacancies at the end of 1957 , compared with 1,461 at the end of 1956 . Training courses and attachments were arranged for 2,925 men and women in the service of overseas governments, compared with 2,752 in 1956 .

The recession in world commodity prices in 1957 had little effect on the territories, and taking the vear as a whole the prices of most Colonial products, except copper and sisal, were as high or higher than in 1956. Output continued to rise and the total gross domestic product is estimated as some 4 per cent above the 1956 level of about $£ 3,100$ million, the greatest proportionate increase being in the West Indian territories, where the value of exports rose by 12 per cent compared with a general increase of 2 per cent. The volume of exports of primary products rose only slightly.

After two years experimental work in the Western Region of Nigeria, 2,000 farmers were trained in their villages in spraying against capsid pest of cocoa. The extensive spraying campaign against blackpod continues, but control of swollen shoot disease has lost ground. Farmer-training in the control of blackpod and capsid on cocoa continued in the Eastern Region and about one-third of the 8,000 cocoa farmers in the Southern Cameroons sprayed their cocoa against blackpod disease with excellent results. In Kenya use of parathion sprayed from aircraft at night showed great promise for control of infestation by the Quelea bird (Sudan Dioch), and use of dieldrin for control of white stem borer of coffee and of DDT/BHC dust for cotton pests continued to spread in Tanganyika. A programme of research and control of the serious incidence of insect pests of cotton in the Aden Protectorate is in progress. Research continued into the most suitable types of fertilizers for individual soils and crops, and use of fertilizers continued to increase. The territories continued to receive expert

* Colonial Office. The Colonial Territories 1957-1958. Pp. xxv+ 171. (Cmnd. 451.) (London: H.M. Stationery Office. 1958.) 98. net. assistance under the Expanded Technical Aid Programme. Two teams of experts visited Jamaica, Trinidad, British Honduras and Dominica to survey costing methods and research needs, respectively, of the citrus industries.

Effective control of the major epizootic diseases continued in the West African territories, but trypanosomiasis continues to be a serious problem in East and Central Africa.

Public expenditure on development continued at a high rate and expenditure from Colonial Development and Welfare Funds rose by about $£ 1$ million, but was still only about three-quarters of the annual average available under the 1955 Colonial Develop. ment and Welfare Act. New development plans were drawn up in Jamaica and Trinidad, and during the year power supplies became available for Kenya from the Owens Falls hydro-electric plant in Uganda. A new road from Western Uganda to the Belgian Congo was completed, work begun on the construction of a deep-water harbour in Barbados and the first hydro-electric plant in British Guiana came into operation.

Facilities for education increased in nearly every territory, as did the numbers using them. Of the 3,400 students in the two universities and three university colleges, 1,075 were in the University of Hong Kong, 749 at University College, Ibadan, 710 at the University College of East Africa, Makerere College, and 566 at the University College of the West Indies. Teaching and administrative staffs have also expanded, and University College, Ibadan, has now a fully established medical school with a new teaching hospital. In co-operation with the Nigerian College of Arts, Science and Technology, which was formally opened in November, a faculty of engineering is being established, and the University College of the West Indies is considering the establishment of a faculty of agriculture. Allocations to these university institutions under the Colonial Development and Welfare Funds for capital expenditure for the 1955-60 quinquennium total $£ 6,853,000$. The Royal University of Malta was the subject of an investigation by a Royal Commission, and the Governments of Kenya, Uganda, Tanganyika and Zanzibar jointly published a paper outlining their future plans for higher education.

Progress in preventive and social medicine has been in two main directions : by a widely developed attack on communicable disease by mass campaigns of treatment, immunization or destruction of insect vectors; and by much greater attention to the needs of the family and the individual through the medium of health centres, specialized clinics and an elaboration of domiciliary care. Control and ultimate elimination of malaria still constitute a major challenge, but the effects of a more enlightened outlook on leprosy are apparent in the recognition of the need for social rehabilitation of those cured.

Of the 9,923 Colonial students in the United Kingdom and the Irish Republic at the end of 1957, 1,298 held scholarships and 2,709 were at universities. Of the total, 3,360 were from West Africa and 3,096 from the West Indies ; 867 were studying engineering, 745 medicine, 308 science, 228 economics, 89 agriculture and 69 dentistry. Tribute is again paid, here 
and in respect of information services, to the work of the British Council. It is estimated that $1,033,000$ U.S. dollars will be spent on the United Nations Expanded Programme of Technical Assistance in the British territories in 1958 compared with $1,271,000$ dollars in 1957. Under the Fulbright Agreement nine American teachers were posted to schools in Western Nigeria, St. Helena, Antigua, Grenada, Jamaica and Montserrat, and nine senior research workers attached to university and research institutions in East Africa, Northern Nigeria, Hong Kong, Jamaica and Trinidad, while two scientists continued research into the preservation of wild life in the game reserves of Uganda. Travel grants enabled lecturers from University College, Ibadan, the University College of the West Indies and the University of Malaya to visit the United States for research and to give lectures. An Overseas Visual Aid Centre has been established in London with the joint support of the Government and the Nuffield Foundation to further the use of visual and audio-visual aids in education.

\section{SOLID STATE PHYSICS \\ CONFERENCE IN BRUSSELS}

\begin{abstract}
$\mathrm{A}^{\mathrm{S}}$ part of the activities associated with the Solid State Physics and its applications to electronics and telecommunications was held in Brussels during June 2-7. The meeting had the patronage of the King of the Belgians and the support of the International Union of Pure and Applied Physics. It was regarded as appropriate because of the stress laid by many exhibitors on contemporary scientific achievements. After an introductory lecture by W. Shockley, the 750 participants from twenty-four countries divided up to listen to papers which were grouped in five parallel sessions throughout the six days of the conference.
\end{abstract}

It was inevitable that such a meeting would be dominated by discussions of the properties of semiconductors, their theory, and the main applications in transistors, phosphors and electroluminescence. There were also sessions on ferrites. Despite the extent of the field covered, its unity, so far as basic ideas are concerned, became very clear as the meeting progressed. This proved to be a stimulus to many participants, who regretted the large number of papers offered rather than the spread of topics.

The areas of activity in the field of pure semiconductors include equilibrium properties such as susceptibility measurements, transport phenomena, the study of barrier layers and surfaces, of noise, life-times and recombination, optical properties, the growth of, and imperfections in, single crystals, and the changes induced by irradiation. All these topics, and others on the more applied side, were discussed at this meeting, as they were at the last similarly international meeting at Garmisch in 1956 (see Nature, 198, 1156; 1956). A slight change of emphasis has, of course, occurred. For example, at Garmisch considerable interest was shown in the newly discovered phonon drag effect, which implies, for example, that long wave-length phonons exert a drag on the charge carriers, and contribute rather strongly to thermal conduction. Little was said about this effect in Brussels. On the other hand, the properties of electrons which are not in equilibrium with the lattice owing to the effects of an applied electric field-the so-called 'hot electrons'-received much more attention than they did at Garmisch, and this promises to remain an active field.

For example, J. Bok (École Normale Supérieure, Paris) reported attempts by thermionic emission experiments to obtain direct evidence of the temperature of hot electrons. S. H. Koenig (I. B. M. Watson Laboratories, Columbia University) emphasized again that the hot electron distribution function responds very rapidly (within less than $10^{-8} \mathrm{sec}$. ) to changes in the applied field. In many aspects of these effects theory still lags behind experiment. This became particularly clear from a talk by $R$. Stratton (Metropolitan-Vickers Electrical Co., Manchester), who discussed theories of the dependence of electron mobilities on the electric field.

As the applied field is increased, the hole and electron temperature rise, and in due course breakdown occurs. In $p-n$ junctions the breakdown is believed to be of the avalanche type. This was discussed for germanium by B. M. Wul (Lebedew Institute, Moscow). He showed that the coefficient of impact ionization for holes is about twice that for electrons. Recent work for silicon (Chynoweth, A. G., Phys. Rev., 109, 1537; 1958) is of interest here for comparison. The properties of hot electrons may also be expected to affect the current - voltage relation of $p-n$ junctions for high forward currents. This was discussed by A. K. Jonscher (General Electric Co., Wembley), the suggested form of the relation being $I^{1 / 2}=A V(V-B)$.

In this field of barrier-layer physics, attention was directed by several speakers to the measurement of the working temperature in the barrier (which has a pronounced effect on the properties of silicon and germanium rectifiers). Considerable interest was also shown in narrow germanium $p-n$ junctions containing high concentrations $\left(10^{18}\right.$ to $\left.10^{20} \mathrm{~cm}^{-3}\right)$ of impurities. In such structures the Fermi-level can lie below the top of the valence band on one side, and above the bottom of the conduction band on the other side. This gives rise to stability against thermal shock, and to a forward current-voltage characteristic which exhibits negative resistance (for preliminary results, see Esaki, L. (Tokyo), Phys. Rev., 109, 603; 1958). An incidental point of interest is that the direction of rectification is opposite to the usual one, and so is in agreement with that suggested in 1932 on the hypothesis of electron tunnelling.

It appears that semiconductor surfaces are being investigated increasingly by means of adsorption characteristics. The possibility of either mobile or localized adsorbed films of various kinds on germanium surfaces was envisaged by M. J. Sparnaay (Philips Research Laboratories, Eindhoven), and by H. Statz (Raytheon Co., Waltham, Mass.). Lowenergy electron diffraction and work-function measurements were used by $\mathrm{H}$. E. Farnsworth et al. (Brown University, Rhode Island) to study the structure and adsorption characteristics of clean germanium surfaces. He showed that surface atoms, displaced on a clean surface, appear to be restored to 